University of Nebraska - Lincoln

DigitalCommons@University of Nebraska - Lincoln

$6-2020$

Colecciones textiles etnográficas del Gran Chaco Sudamericano del Museo Etnográfico “J. B. Ambrosetti” y el estudio de su materialidad: un desafío a la mirada occidental sobre los otros no-occidentales

Mariana Alfonsina Elías

Follow this and additional works at: https://digitalcommons.unl.edu/pctviii

Part of the Art and Materials Conservation Commons, Fiber, Textile, and Weaving Arts Commons, Indigenous Studies Commons, Latin American Languages and Societies Commons, Museum Studies Commons, and the Other History of Art, Architecture, and Archaeology Commons

This Article is brought to you for free and open access by the Centre for Textile Research at DigitalCommons@University of Nebraska - Lincoln. It has been accepted for inclusion in PreColumbian Textile Conference VIII / Jornadas de Textiles PreColombinos VIII (2019) by an authorized administrator of DigitalCommons@University of Nebraska - Lincoln. 


\title{
Colecciones textiles etnográficas del Gran Chaco Sudamericano del Museo Etnográfico “J. B. Ambrosetti” y el estudio de su materialidad: un desafío a la mirada occidental sobre los otros no-occidentales
}

\author{
Mariana Alfonsina Elías ${ }^{1}$ \\ 1. Área de Colecciones Etnográficas, Museo Etnográfico “J. B. Ambrosetti”, Facultad de Filosofía y Letras, Universidad de \\ Buenos Aires. E-mail: alfonelias75@gmail.com
}

\begin{abstract}
Resumen
El Museo Etnográfico “J. B. Ambrosetti” (Facultad de Filosofía y Letras, Universidad de Buenos Aires) guarda en su acervo un conjunto amplio, diverso y poco conocido de producciones textiles de distintos pueblos originarios del Gran Chaco Sudamericano. Las mismas han ingresado a la institución entre fines del siglo XIX y las primeras cuatro décadas del siglo XX.

El estudio que vengo desarrollando de varios aspectos de la materialidad de los objetos textiles que conforman dichas colecciones- materia prima, técnicas/ estructuras textiles, diseños, colores, evidencias de uso, etc.- ha implicado la necesaria problematización de nuestra mirada occidental y de nuestras representaciones sobre los pueblos "no- occidentales" que los produjeron y los usaron en el contexto temporal e histórico mencionado.

En este sentido, en este trabajo me interesa dar cuenta de un corpus particular de objetos textiles etnográficos de los pueblos originarios del Gran Chaco Sudamericano presentes en las colecciones abordadas. El estudio de distintos aspectos de su materialidad pone en cuestión, siguiendo a James Clifford, la categoría de lo "típicamente tradicional" que ha guiado a los "recolectores de cultura antropológicos" y el ocultamiento, en el relato del museo occidental moderno, de sus historias específicas de producción y adquisición.
\end{abstract}

Palabras claves: Textiles, Gran Chaco, colecciones etnográficas, apropiación, mercantilización.

\begin{abstract}
The Ethnographic Museum “J. B. Ambrosetti” (Faculty of Philosophy and Letters, University of Buenos Aires) keeps in its collection a wide, diverse and little-known set of ethnographic textiles, products of different peoples originating in the South American Grand Chaco. They have entered the institution between the end of the 19th century and the first four decades of the 2oth century.

My study of several aspects of the materiality of the textile artifacts that make up these collections - raw material, textile techniques / structures, designs, colors, evidence of use, etc. - has implied a necessary problematization of our western gaze and of our representations about the "non-western" peoples that produced them and used them in this temporal and historical context.

In this sense, I am interested in giving an account of the particular corpus of ethnographic textile objects of the original peoples of the South American Grand Chaco present in the collections. The study of different aspects of their materiality calls into question, following James Clifford, the category of "typically traditional" that has guided "anthropological culture collectors" and concealment, in the narrative of the modern western museum, of its specific stories of production and acquisition.
\end{abstract}

Keywords: Textiles, Gran Chaco, ethnographic collections, appropriation, commodification.

DOI: $10.32873 /$ unl.dc.zea.1218

Published in PreColumbian Textile Conference VIII / Jornadas de Textiles PreColombinos VIII, ed. Lena Bjerregaard and Ann Peters

(Lincoln, NE: Zea Books, 2020). https://digitalcommons.unl.edu/zeabook/ 


\section{Résumé}

Le musée ethnographique "J. B. Ambrosetti” (Faculté de Philosophie et des Lettres, Université de Buenos Aires) conserve dans ses collections un ensemble vaste, divers et peu connu de textiles ethnographiques, produits par différentes personnes originaires du Gran Chaco sud-américain. Ils ont été intégrés au musée entre la fin du XIX siècle et les quatre premières décennies du XX siècle.

Mon étude sur les différents aspects de la matérialité des textiles qui composent la collection -matière première, techniques/structures textiles, motifs, couleurs, traces d'utilisation, etc. - a impliqué la problématisation de notre regard occidental et de nos représentations des peuples "non-occidentaux" qui les produisent et les utilisent dans ce contexte temporel et historique.

En ce sens, il m'intéresse de prendre en compte un corpus particulier de textiles ethnographiques des peuples du Gran Chaco sud-américain présents dans la collection. L'étude sur les divers aspects de leur matérialité remet en cause, en accord avec James Clifford, la catégorie du "typiquement traditionnel" qui a guidé les "collectionneurs d'anthropologie culturelle" et la dissimulation, dans le récit du musée moderne, de leurs histoires spécifiques de production et d'acquisition.

Mots-clés: Textiles, Gran Chaco, collections ethnographiques, appropriation, marchandisation.

El Museo Etnográfico “J. B. Ambrosetti” (Facultad de Filosofía y Letras, Universidad de Buenos Aires) guarda en su acervo un conjunto amplio, diverso y poco conocido de objetos textiles de distintos pueblos originarios del Gran Chaco Sudamericano que ingresaron al mismo entre fines del siglo XIX y las primeras cuatro décadas del siglo XX. El estudio de distintos aspectos de su materialidad ha implicado una necesaria problematización de nuestra mirada occidental y de las representaciones de los pueblos no-occidentales que los produjeron y los usaron así como de dichos objetos textiles. La materialidad de los mismos en relación con sus historias de recolección y producción pone en cuestión la categoría de lo "típicamente tradicional" que ha guiado a los "recolectores de cultura antropológicos" así como el ocultamiento, en el relato del museo occidental moderno, de sus historias específicas de producción y adquisición (Clifford 1995: 274), y evidencia las relaciones históricas de poder tras las mismas (Clifford 1995: 262).

Este ocultamiento de las historias específicas de la producción y adquisición se observa en la forma en que generalmente se piensan y estudian los objetos etnográficos producidos por los otros no-occidentales, exigiendo que los mismos respondan a un criterio de autenticidad basado en dos aspectos: producidos para ser específicamente usados por las sociedad en las que se produjeron y con materiales "propios" de aquellas sociedades, quedando ocultas las relaciones con Occidente, es decir, con la instancia colonial y hegemónica.

En este trabajo desarrollaré dos casos de objetos textiles producidos por distintos pueblos indígenas del Gran Chaco Sudamericano, de las primeras décadas del siglo XX, y pertenecientes a las colecciones etnográficas del Museo Etnográfico “J. B. Ambrosetti”, cuyas evidencias materiales cuestionan los dos aspectos del criterio de autenticidad que he mencionado en el párrafo anterior. En primera instancia desarrollaré el caso de un corpus de bolsas de lana cuya técnica de elaboración no integra el catálogo de técnicas consideradas "tradicionales" para la producción de bolsas entre los pueblos originarios del Gran Chaco. En segundo lugar, me centraré en una colección de fajas compradas por el Museo Argentino de Ciencias Naturales "Bernardino Rivadavia” al etnógrafo suizo Alfred Métraux en el año 1934, cuyas escasas evidencias de uso nos permite preguntarnos si su producción ha estado sólo destinada a su uso dentro de la sociedad que las creó o también a su venta a los "blancos".

\section{Marco teórico}

En su libro Dilemas de la cultura, James Clifford se concentra en la recolección de objetos por parte de los museos, abordando críticamente ciertas características de dicha práctica. Citando el estudio de Stewart On longing, señala que éste muestra el modo que las colecciones, y en forma más notable, los museos, crean la ilusión de la representación adecuada de un mundo arrancando primero los objetos de sus contextos específicos y haciendo que ellos "representen" totalidades abstractas y aisladas: una máscara bambara, transformándose en una metonimia etnográfica de la cultura bambara. El sistema de clasificación para almacenar y exhibir los objetos oculta las historias específicas de la producción y apropiación de los mismos. Stewart argumenta que en el museo occidental moderno "la ilusión de una relación entre cosas toma el lugar de una relación social”, de este modo se ocultan las relaciones históricas de poder tras el trabajo de la adquisición (Clifford 1995: 262). En estrecha relación con lo anterior, Clifford señala: 
"Los recolectores de cultura antropológicos han reunido lo que parece ser típicamente "tradicional”, lo que por definición se opone a la modernidad. Desde una compleja realidad histórica (que incluye los encuentros etnográficos actuales), seleccionan lo que da forma, estructura y continuidad a un mundo. Lo que es híbrido o "histórico" en un sentido emergente ha sido recolectado y presentado como sistema de autenticidad con menos frecuencia." (Clifford 1995: 274)

En estos párrafos de James Clifford se señalan algunas problemáticas sobre cómo Occidente representó a través de las colecciones de sus museos a los otros-no occidentales: por un lado dando prioridad a lo considerado "típicamente tradicional" (puro), aislando, en sus narrativas, a los objetos de sus contextos coloniales de recolección y también de producción, y de esta manera ocultando la relaciones sociales, históricas de poder inscriptas en los mismos.

Distintos estudios antropológicos y especializados en textiles, han puesto en cuestión la categoría de lo "tradicional" y puro para la representación y el reconocimiento de las culturas no occidentales, dando relevancia a las categorías de "apropiación” y “agencia” en la producción de su cultura material.

Guillaume Boccara habla de una "antropología diacrónica” que rechaza la perspectiva de la "pureza original” para pensar las culturas como objetos de reelaboración permanente, rebatiendo la concepción de que una sociedad, cuando adopta un elemento de otra, sufre necesariamente un proceso de aculturación impuesta, deculturación o de contaminación. Señala que “(...) las culturas dominadas utilizan significantes de las sociedades dominantes para producir otros significados. De modo que resulta equivocado pretender explicar la transformación de una tradición como si se tratase de una extinción, de una decadencia o de una contaminación" (Boccara 2005: 10-11). En estrecha relación con estos planteos, Janet Catherine Berlo sostiene que el "arte textil" de Latinoamérica no es una mera respuesta pasiva y defensiva a cinco siglos de colonialismo y propone considerar los procesos de apropiación implicados, posicionando a los pueblos indígenas como agentes activos de sus propios estilos artísticos y no como simples recipientes pasivos de una cultura hegemónica que constantemente erosiona y socava su cultura "tradicional" (Berlo 1996: 452-453).

En estos abordajes, mediante la consideración crítica de los conceptos de aculturación (Boccara 2005) y el acento en los procesos de apropiación (Berlo 1996), juega un rol central la noción de agencia de los indígenas en sus relaciones con las sociedades coloniales, pensándolos no como sujetos pasivos frente a una cultura hegemónica sino como sujetos activos que a través de cada una de sus prácticas sociales resignifican y se apropian de aquello que proviene de dicha cultura hegemónica. Siguiendo a Sherry Ortner, “[...] está en juego la importancia de cuestionar el efecto totalizador de formaciones como el colonialismo o el racismo y de tratar de observar la manera en la que los actores dominados conservan la 'agencia' (...)” (Ortner 2016: 170).

Se debe señalar que, estas propuestas, a su vez, permiten dar cuenta de las relaciones históricas de poder en las que se producen y produjeron los objetos de distintos pueblos no-occidentales. Pese al interés señalado por Clifford de los recolectores de cultura antropológicos por lo "puro" y "tradicional", las colecciones etnográficas de distintos museos están integradas por objetos "híbridos” más comúnmente de lo que podemos llegar a imaginar. Esto se evidencia en el estudio de distintos aspectos de su materialidad; son necesarias herramientas teóricas para poder abordarlas.

En relación con esto último, nos interesan los planteamientos de Ruth Phillips y Christopher Steiner cuando señalan que los objetos de los otros culturales, desde fines del siglo XIX, han sido apropiados principalmente dentro de dos categorías: el artefacto o espécimen etnográfico y el trabajo de arte, y que ambas clasificaciones (construcciones) enmascararon "lo que se había convertido, hacia fines del siglo XVIII, en uno de los rasgos más importantes de los objetos: su funcionamiento como mercancías (commodities) circulando en el espacio discursivo de una economía capitalista emergente." (Phillips y Steiner 1999: 3) Estos autores señalan que ha habido un sorpresivo silencio sobre los procesos de mercantilización en las historias del arte estándar y en las etnografías (Phillips y Steiner 1999: 3). Estos procesos de mercantilización relacionados con la producción, uso y circulación de los objetos de los otros no-occidentales han sido uno de los aspectos relevantes de la extensión global del poder colonial occidental; sin embargo, tanto los estudiosos como los consumidores occidentales los han obviado y, donde el hecho de la mercantilización podía ser ocultado, los objetos ocupaban las categorías del esquema binario de arte y artefacto. Mientras que, cuando la naturaleza mercantil era muy evidente, los objetos eran calificados de inauténticos o falsos (Phillips y Steiner 1999: 4).

Considero que abordar actualmente colecciones etnográficas, recolectadas a principios del siglo XX, requiere tener en cuenta estas problematizaciones puesto que también nos plantea y nos cuestiona sobre las representaciones que los profesionales de museos antropológicos e investigadores occidentales hemos construido respecto a los otros nooccidentales y su cultura material. 


\section{Metodología}

Un medio para el estudio de estas problemáticas es el abordaje de distintos aspectos de la cultura material de los otros no-occidentales guardada en los museos, ya que a través de la aplicación de distintos métodos de análisis de la misma se pueden encontrar indicios de estas realidades híbridas, coloniales y complejas de producción, uso y consumo.

En el caso específico de los textiles, nuestro abordaje de las colecciones textiles del Gran Chaco Sudamericano del Museo Etnográfico “J. B. Ambrosetti” se basó, en primera instancia, en el análisis de distintos aspectos, a saber: materias primas, estructuras textiles/ técnicas, formatos, medidas, configuraciones de diseños, ubicación de los mismos en el campo textil y colores. Por otro lado, se llevó a cabo el relevamiento de las evidencias de uso presentes en ellos. Se ha trabajado con fichas de registro de textiles específicas y se ha organizado la información obtenida en archivos Excell que permitieran su puesta en comparación y recuperación de la misma.

Simultáneamente, se ha llevado a cabo el relevamiento bibliográfico, de fuentes y diverso tipo de documentación escrita y visual de archivo y catálogos de ingreso originales de los objetos al museo con el fin de recuperar información sobre el uso y la producción de los mismos entre las poblaciones indígenas a las que son atribuidos y sobre las historias de recolección e ingreso al museo. Esto nos permitió recuperar los contextos históricos de recolección y formación de las colecciones, entre otras cosas.

\section{Bolsas tricotadas de lana}

A partir del estudio de las estructuras textiles presentes en los objetos tejidos de distintas poblaciones indígenas de la región Gran Chaco Sudamericano que se encuentran en las colecciones etnográficas del Museo Etnográfico "J. B. Ambrosetti", he podido diferenciar un corpus de bolsas que presenta una estructura textil particular a causa de su probable procedencia y por su diferenciación respecto a las estructuras textiles presentes en objetos con funciones similares.

Me refiero a un corpus de 107 bolsas de lana atribuidas en su mayoría a grupos Wichí. La particularidad que presentan es que en el recipiente de las mismas he registrado una estructura de tricotado (knitting en Emery 2009: 40). ${ }^{2}$ Esto las diferencia de otras bolsas de formato cuadrangular, elaboradas la mayoría de ellas con caraguatá/ chaguar ${ }^{3}$ en tejido de malla (ver looping en Emery 2009: 31) (Figura 1). ${ }^{4}$ Este último tipo de bolsas son las que han merecido un tratamiento más extendido por parte de los estudiosos en diversas publicaciones debido a ser consideradas una producción "tradicional” de los pueblos indígenas del Gran Chaco.

Este corpus de bolsas de lana ha ingresado en su mayoría, al Museo Etnográfico “J. B. Ambrosetti”, a través de la donación de las colecciones etnográficas y arqueológicas del Museo Argentino de Ciencias Naturales "Bernardino Rivadavia” en el año 1947. Desarrollaremos brevemente la historia de ingreso de éstas a este último museo, intentando dar cuenta de una parte de sus contextos de recolección y formación.

Las bolsas más tempranas que registré con esta estructura textil corresponden a la colección formada por el etnógrafo Enrique Palavecino en su expedición del año 1929. Una de ellas atribuidas al pueblo Pilagá del oeste de Formosa (Argentina), nueve a los Wichí de Las Lomitas (provincia de Formosa, Argentina) (Catálogo de ingreso de objetos al Museo Argentino de Ciencias Naturales "Bernardino Rivadavia”, 1929-1945).

Cinco bolsas del corpus fueron recolectadas por este mismo etnógrafo en su expedición del año 1935, tres de ellas entre los Wichí de Bazán (Formosa, Argentina) y dos entre el grupo Wo Pelaj (Wichí) en la provincia de Salta (Argentina) (Catálogo de registro de objetos al Museo Argentino de Ciencias Naturales "Bernardino Rivadavia”, 1929-1945).

En el año 1937, Palavecino realiza otra expedición al Chaco argentino, y recolecta, en la localidad de Embarcación (Salta, Argentina), 63 bolsas atribuidas a los "Matacos del Pilcomayo" (Wichí). En una nueva expedición etnográfica del año 1938, Palavecino forma una colección que

2 Decidimos usar el término tricotar en lugar de knitting tal como lo propone Ann P. Rowe en "Términos textiles en castellano" (Rowe 20o6: 448). El tricotado integra el conjunto de estructuras textiles formadas por un elemento continuo que trabaja consigo mismo formando hileras horizontales; cada lazada es hecha con la parte del hilo más cercana al borde del tejido y es llevada a través de una lazada anterior. El trabajo, entonces, avanza hacia arriba, en dirección opuesta a las otras estructuras de malla (Ver knitting en Emery 2009: 40).

3 Caraguatá o chaguar son los nombres dados, en las zonas de influencia guaraní y quichua, respectivamente, a plantas pertenecientes a la familia de las bromeliáceas. Las fibras textiles se obtienen de las hojas (Arenas 1997: 127).

4 Con este término nos referimos a las estructuras formadas por un elemento continuo (generalmente, un hilo) que trabaja consigo mismo formando hileras horizontales de mallas que se ligan a las mallas de las hileras anteriores. Para elaborar una malla es necesario que el hilo pase, en toda su longitud, por la malla de la hilera anterior (Emery 2009: 30). Las estructuras textiles de malla registradas en las bolsas de caraguatá/chaguar de formato cuadrangular de las colecciones estudiadas, según la terminología de Emery, son: simple looping (Emery 2009: 31), double interconnected looping, figure-8 (Emery 2009: 33); por otro lado, también se registra cord looping (Seiler-Baldinger 1994: 17). 


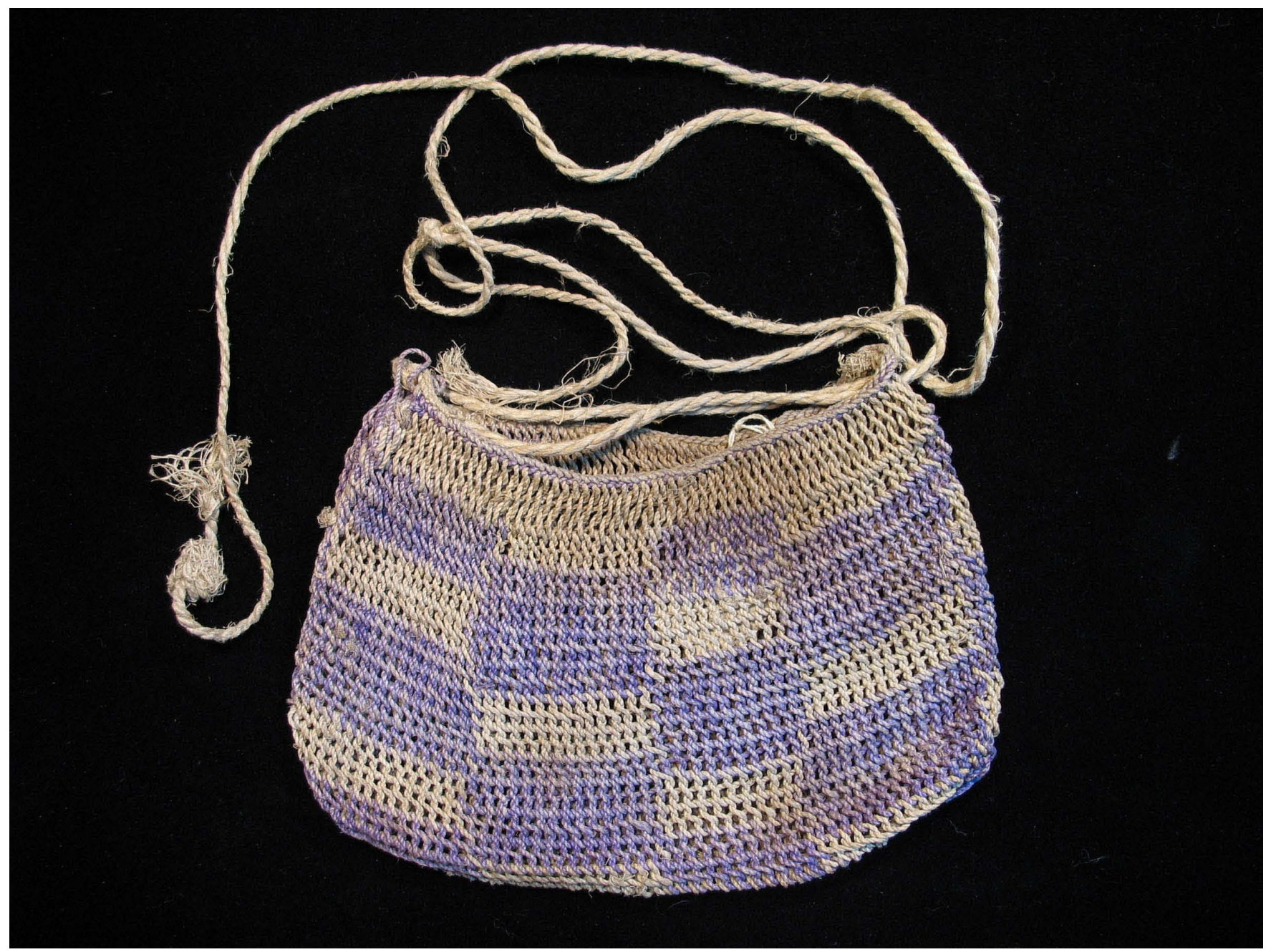

Figura 1- Bolsa de caraguatá/ chaguar en tejido de malla (double interconnected looping) con diseño de damero- Wichí- Colección Excursión E. Palavecino, 1935- Museo Etnográfico “J. B. Ambrosetti”. Fotografía: M. A. Elías

incluye tres bolsas de este tipo. En dos excursiones subsiguientes, en los años 1942 y 1945, este etnógrafo recolecta respectivamente, ocho bolsas atribuidas a los "Mataco del Río Pilcomayo" (Wichí) y tres bolsas, también de los "Mataco del Río Pilcomayo" (Wichí), pero recolectadas en la localidad de Embarcación (Catálogo de registro de objetos al Museo Argentino de Ciencias Naturales "Bernardino Rivadavia", 1929-1945).

Además de las colecciones formadas por Enrique Palavecino, se registran cuatro de estas bolsas en la colección que el Museo Argentino de Ciencias Naturales "Bernardino Rivadavia” compra a la exploradora Wanda Hanke en 1938, recolectadas en Algarrobal (cerca de Embarcación) y atribuidas a los Wichí. Luftensteiner, secretario privado de dicha exploradora, vende al Museo de Ciencias Naturales, en el año 1938, una bolsa de este tipo. Finalmente, se relevan también doce bolsas con estas características en la colección “Comprada a los indios Macá” en el año 1939 por el Museo Argentino de Ciencias Naturales (Catálogo de ingreso de objetos al Museo Argentino de Ciencias Naturales "Bernardino Rivadavia” 1929-1945).

Distintos etnógrafos han realizado breves referencias sobre la presencia de bolsas con estas características entre distintos grupos indígenas del Gran Chaco, aunque en escasos casos se menciona la particularidad de la técnica. Eric von Rosen, en su libro Ethnographical Research Work During the Swedish Chaco-Cordillera Expedition, 1901-1902, presenta el dibujo de una bolsa Chorote con estas características y refiere que las mismas son de uso masculino (Von Rosen 1924: 123 y 125). Max Schmidt, en un artículo sobre los "Matacos Guisnais" (Wichí), menciona que un tipo de bolsa utilizada son las de lana, y es el primero que hace referencia 
a que están fabricadas en "labor de punto" (Schmidt 1937a: 34); también hace mención de su uso y características similares para el pueblo Tapieté (Schmidt 1937b: 50). Alfred Métraux da información sobre la tecnología empleada en la elaboración de estas bolsas de lana, señalando que implicaba el empleo de dos y hasta cuatro agujas de espinas de cactáceas (Métraux 1946: 286).

Más tardíamente, María Delia Millán de Palavecino menciona las bolsas de lana, señalando que están realizadas en "técnica de calceta" y atribuyendo, por primera vez, su difusión, entre los “Matacos del Teuco y Teuquito" (Wichí), a la enseñanza misionera (Millán de Palavecino 1973: 81). José Braunstein muestra, para los Maká, el dibujo de una bolsa de lana similar a las realizadas en tricotado; la denominación dada a estas bolsas era t'otoi witilkuki jukhewle y las usaban los hombres en los bailes, cruzadas en bandolera; en ellas guardaban la pipa, el tabaco y los escarificadores de huesos de animales (Braunstein 1982: 394-397).

A partir del análisis de las estructuras textiles presentes en los recipientes de las bolsas guardadas en el Museo Etnográfico de Buenos Aires se puede señalar que sus características permiten relacionar su elaboración con lo mencionado y descrito por Max Schmidt para los "Matacos Guisnais" (Wichí) y por aquellos estudiosos que hablan de "labor de punto", "técnica de calceta”, etc. Los recipientes del corpus que se desarrollan en este apartado, atribuidas a grupos Pilagá, Wichí y Maká, presentan una estructura de tricotado que corresponde al llamado punto de media (Emery 2009: 40, "stocking stitch"), ya que el tejido que se observa en ellas es tubular. En el mismo, todas las lazadas, que son abiertas, se encuentran sobre una de las caras del tejido y las dos caras de éste presentan apariencias disímiles. En la decoración estructural de estas bolsas se observa un tipo de técnica denominada por Cintia Le Count weaving para los tejidos tricotados andinos (Le Count 1990: 78); la misma consiste en el empleo de dos elementos simultáneos de colores diferenciados, donde el elemento no usado para realizar el diseño en el anverso del tejido es enlazado en cada lazada realizada por el hilo del color usado en el diseño. Las bolsas analizadas presentan mayormente el empleo de dos hilos de dos colores y como máximo tres hilos de tres colores; en este último caso, el hilo que realiza las lazadas del diseño enlaza los dos hilos no usados. En todos los casos analizados por nosotros, el sentido del tejido en los recipientes es desde la base hacia la boca de los mismos, presentando la costura de cierre del recipiente en la base. ${ }^{5}$

La técnica de tricotado es una invención reciente, la cual primero apareció en la Edad Media, probablemente en el mundo Islámico, y se expandió hacia Europa y desde Europa a América (Rowe 1997: 3). Aquí es importante volver a mencionar la referencia de Millán de Palavecino que señala que la técnica fue enseñada por los misioneros entre los "Mataco del Teuco y Teuquito" (Wichí) en Argentina (Millán de Palavecino 1973: 81). Es decir, que esta técnica de tejido, presente exclusivamente en los recipientes de estas bolsas de lana, fue incorporada probablemente entre los pueblos indígenas de la región del Gran Chaco a través de su interacción con distintos actores sociales "blancos" de la sociedad hegemónica.

Resulta importante mencionar que un artefacto socioeconómica y simbólicamente relevante entre distintas poblaciones indígenas del Gran Chaco son las bolsas. La mayoría de ellas están elaboradas en caraguatá/ chaguar en distintos puntos de tejido de malla. Presentan dos formatos básicos (rectangular o cuadrangular y semiesférico) (Millán de Palavecino 1944; Von Koschitzky 1992; Susnik 1982; Braunstein 1982; Arenas 2003; Elías 2012). Según distintos autores, las de formato rectangular o cuadrangular presentan distintos tamaños respondiendo a diversas funciones relacionadas especialmente con su uso por parte de los hombres, a excepción de las de mayor tamaño empleadas también por las mujeres (Millán de Palavecino 1944; Von Koschitzky 1992; Susnik 1982; Braunstein 1982; Montani 2007).

Los recipientes elaborados en tricotado del corpus de bolsas que se analizan en este trabajo sólo presentan un formato rectangular o cuadrangular. Sus medidas máximas son 24cm de alto y 23,5cm de ancho (Elías 2008: 44); sólo se relevan ejemplares de tamaño reducido. Esto coincide con lo señalado por la etnógrafa Branislava Susnik que las bolsas en labor de punto desplazaron a las pequeñas bolsas de caraguatá usadas por los hombres para guardar las leznas, pipas, tabaco o amuletos de caza y usadas en ocasiones festivales (Susnik 1982: 189).

Pese a la diferencia tecnológica implicada en esta técnica en relación con los tejidos de malla o red de las bolsas de caraguatá/chaguar - además de la diferencia entre las estructuras de malla empleadas en las bolsas cuadrangulares de caraguatá ${ }^{6}$ y la estructura de tricotado de las bolsas de lana, en las estructuras de malla o red el hilo debe pasar en toda su longitud por la malla de la hilera anterior, en el tricotado cada lazada es hecha con la parte del hilo más cercana al borde del tejido y es llevada a través de una lazada anterior; el trabajo, entonces, avanza hacia arriba, en dirección

5 Estas características también se observan en corpus de bolsas atribuidos a pueblos Nivaklé (Elías 2012).

6 Remitirse a la nota 4 del presente trabajo para ver las estructuras textiles de malla registradas en las bolsas cuadrangulares de caraguatá/ chaguar. 


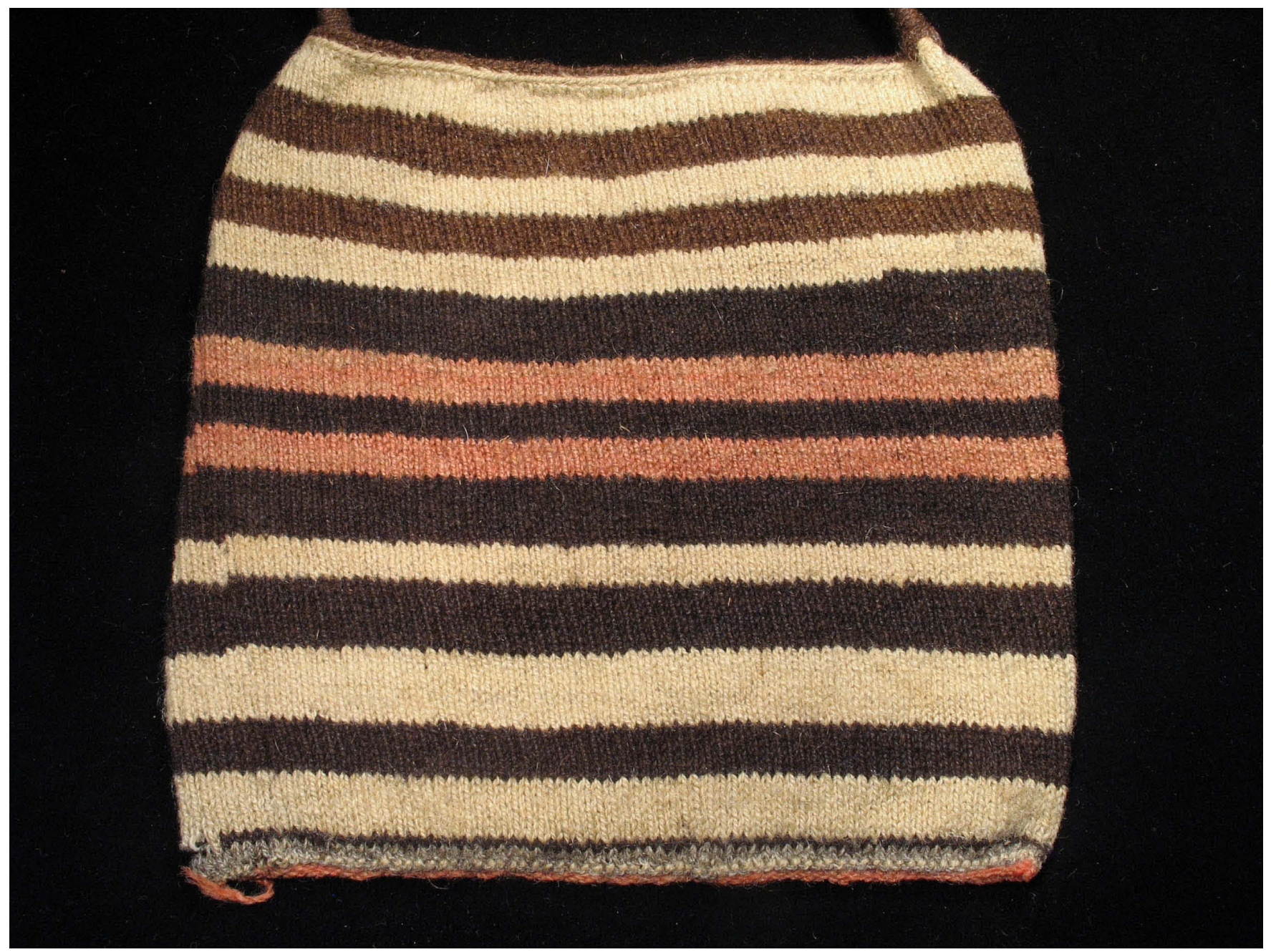

Figura 2- Bolsa tricotada con diseño de líneas y bandas paralelas- Wichí- Colección Excursión E. Palavecino, 1937- Museo Etnográfico “J. B. Ambrosetti”. Fotografía: M. A. Elías.

opuesta a las otras estructuras de malla (Emery 2009: 40; Rowe 1997: 3, 10)-, los pueblos originarios del Gran Chaco la incorporaron para la elaboración de objetos relevantes de su cultura material. Es decir, se evidencian procesos de apropiación de esta técnica procedente de la sociedad hegemónica por parte de las poblaciones originarias de la región .

Esto último se confirma por las características de los motivos y configuraciones de diseños que he relevado en los recipientes tricotados de las bolsas de lana. Se observan líneas y/o bandas rectas horizontales paralelas de dos o tres colores alternas (Figura 2); dameros o ajedrezados formados por cuadrángulos alternados de dos colores (Figura 3); triángulos o trapecios de dos colores, organizados alternadamente sobre un eje horizontal (Figura 4); líneas zigzag verticales (Figura 5); configuraciones de líneas verticales quebradas en ángulos rectos formadas por dos líneas o dos grupos de líneas en relación especular, con un motivo cruciforme en el eje de simetría (Figura 6) . Finalmente, configuraciones de diseños con rombos se registran frecuentemente en las bolsas de lana con recipientes tricotados, con diversas organizaciones: rombos lineales y concéntricos, alineados vertical y horizontalmente o formando una retícula (Figura 7).

Estos motivos y configuraciones de diseños también se registran en las bolsas cuadrangulares en tejido de malla de caraguatá/ chaguar. Distintos autores los describen y nos informan sobre las significaciones de los mismos. Entre los Wichí, los diseños de bandas paralelas se observan en pequeñas bolsas rectangulares elaboradas en enlazado en cordón, son denominados athlutset'aj (panza de iguana) (Von Koschitzky 1992: 45; Montani 2007: 39). Según Montani, entre los pueblos Wichí del oeste de Formosa, distintos di- 


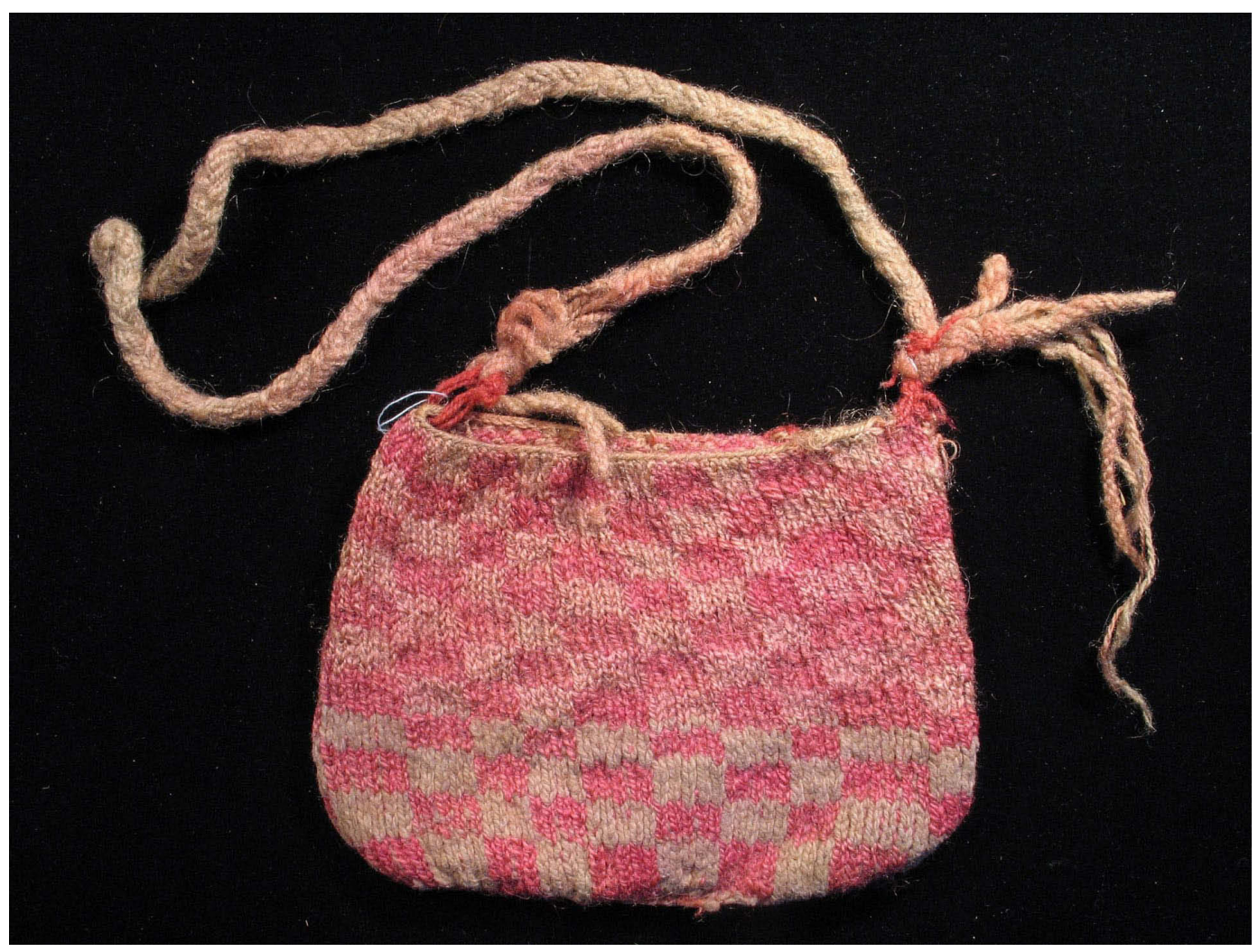

Figura 3- Bolsa tricotada con diseño de damero- Wichí- Colección Excursión E. Palavecino, 1929- Museo Etnográfico “J. B. Ambrosetti”. Fotografía: M. A. Elías

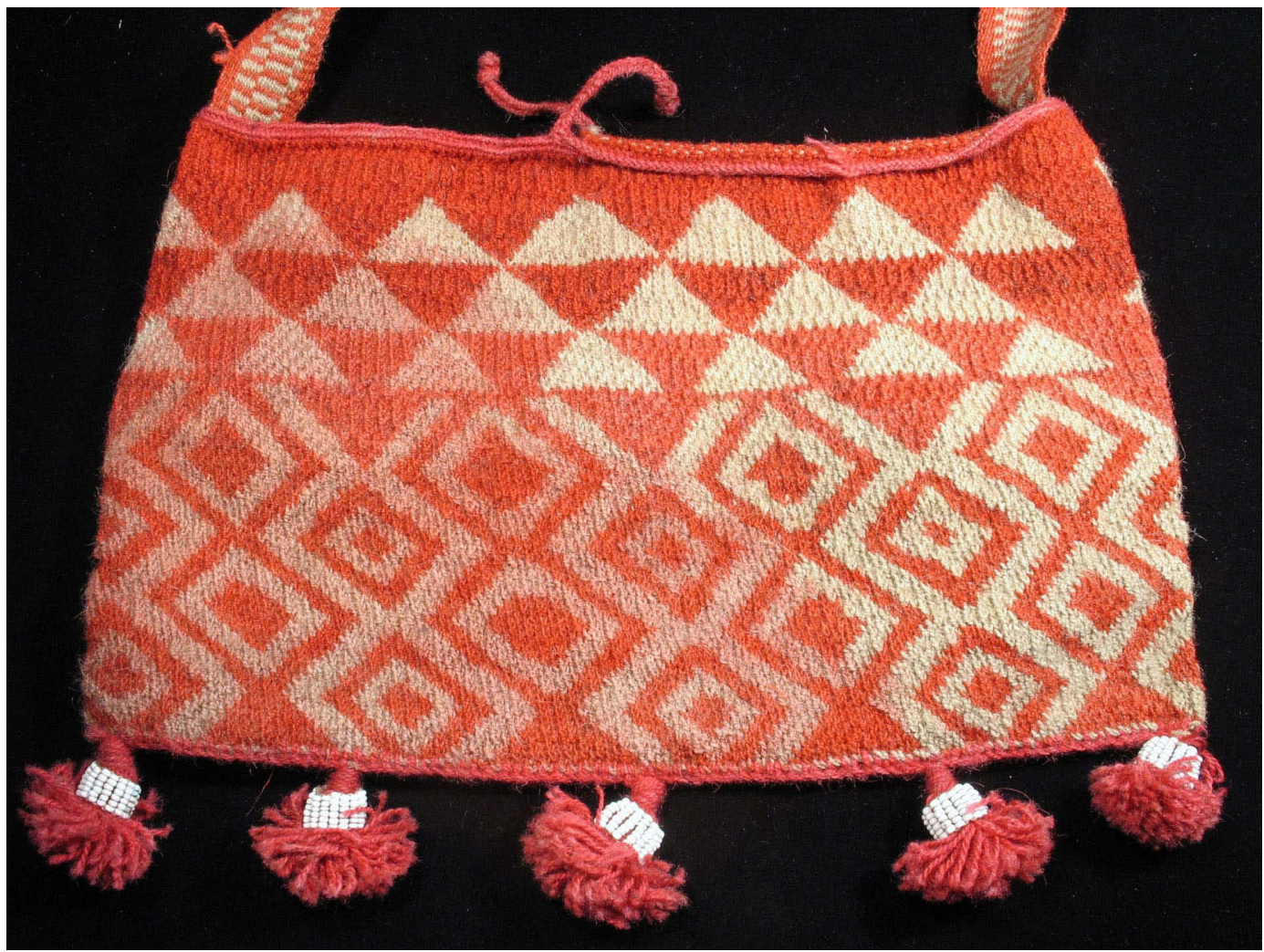

Figura 4- Bolsa tricotada con diseño de triángulos- Maká- Colección comprada a los Maká por el Museo Argentino de Ciencias Naturales, 1939- Museo Etnográfico “J. B. Ambrosetti”. Fotografía: M. A. Elías. 


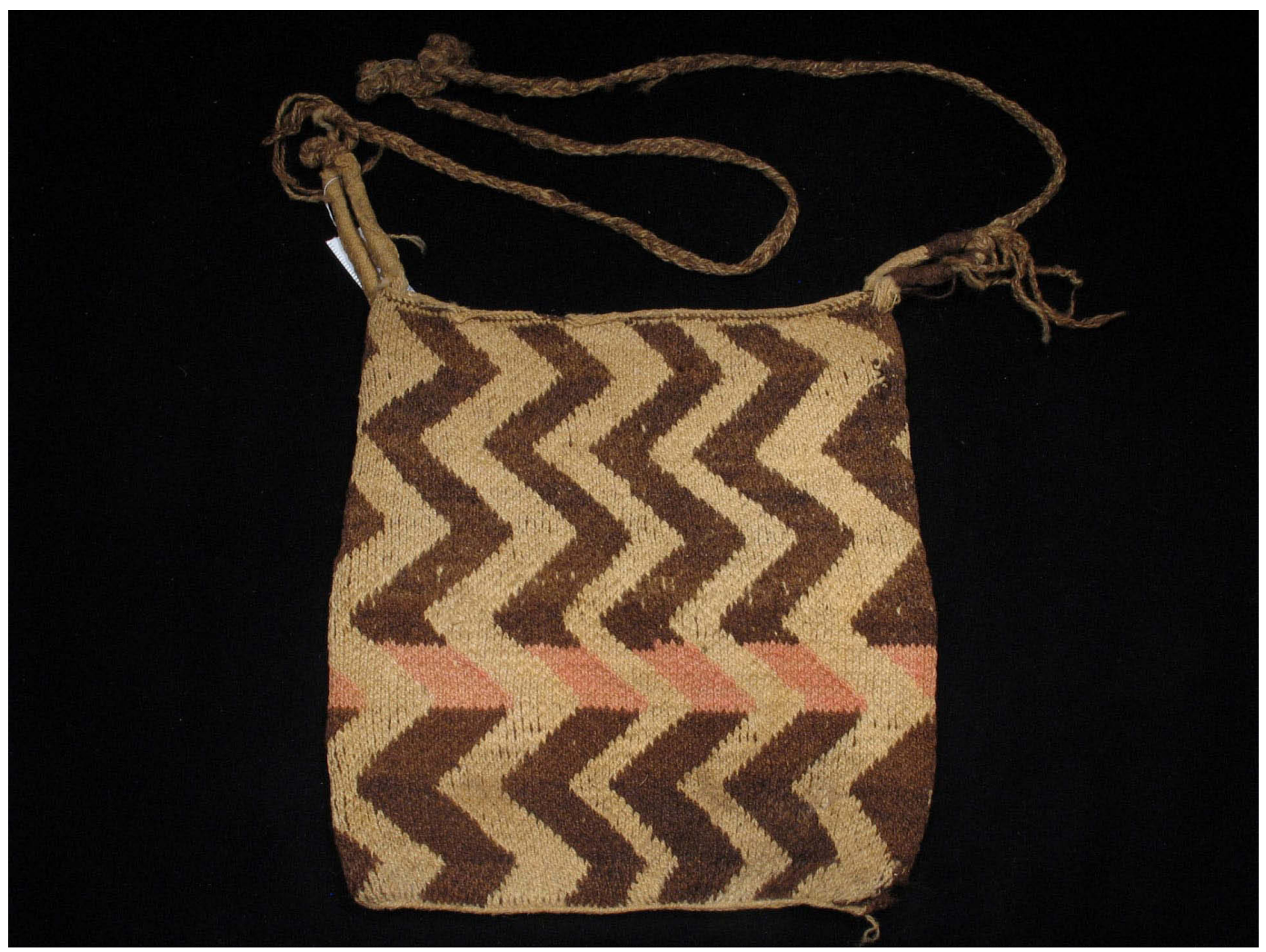

Figura 5- Bolsa tricotada con diseño de líneas zigzag- Wichí- Colección Excursión E. Palavecino, 1937- Museo Etnográfico “J. B. Ambrosetti”. Fotografía: M. A. Elías.

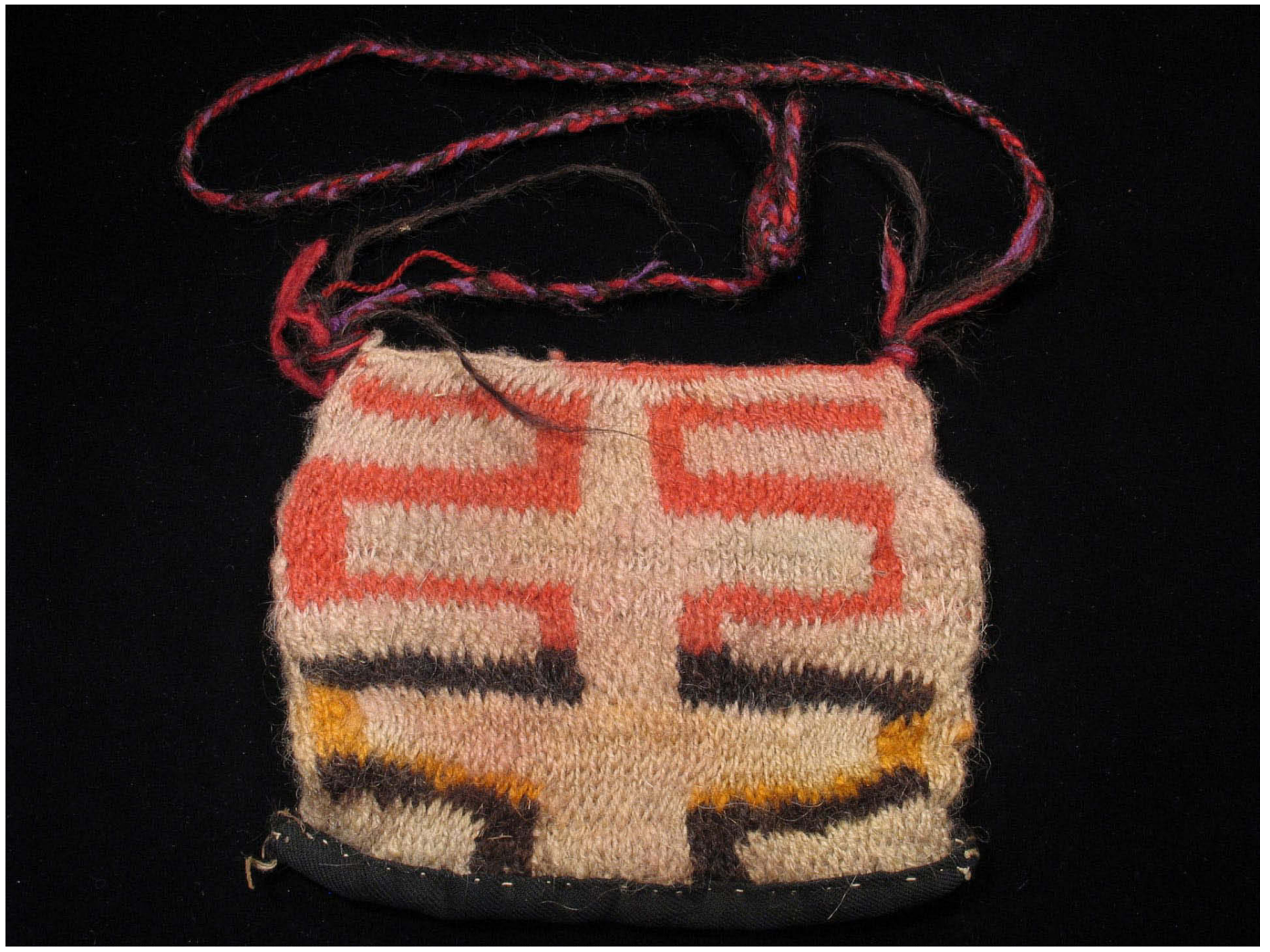

Figura 6- Bolsa tricotada con diseño de líneas quebradas en ángulos rectos- Wichí- Colección Excursión E. Palavecino, 1929- Museo Etnográfico “J. B. Ambrosetti”. Fotografía: M. A. Elías. 


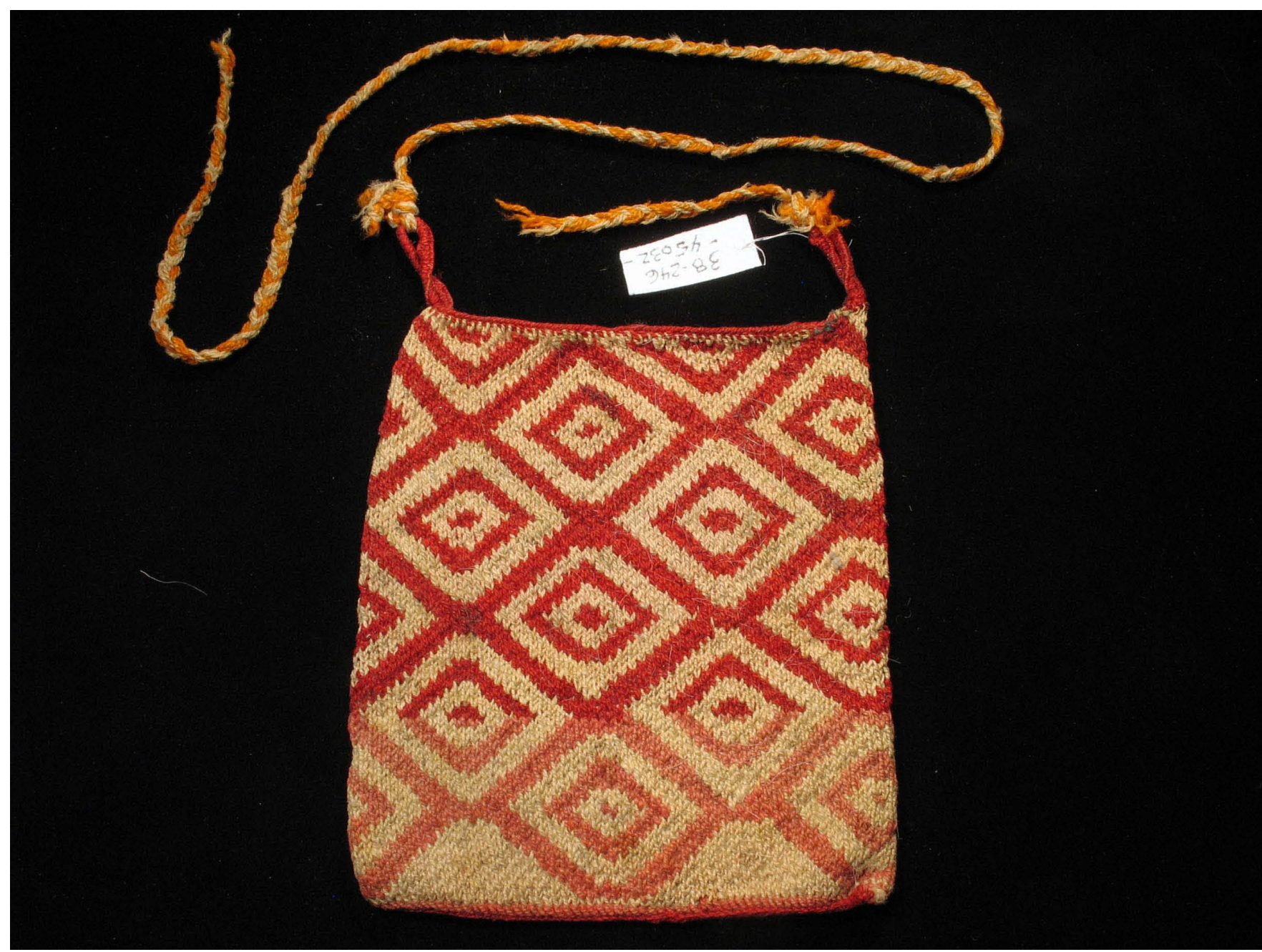

Figura 7- Bolsa tricotada con diseño de retícula de rombos concéntricos- Wichí- Compra a Wanda Hanke, 1938- Museo Etnográfico "J. B. Ambrosetti”. Fotografía: M. A. Elías.

seños romboidales de las bolsas en tejido de malla de caraguatá/ chaguar representan ojos de pájaros (Montani 2007: 48). La denominación de los Wichí para los diseños de líneas zigzag verticales de las bolsas de caraguatá se traduce como "codos" (katoltas, katul-tas)7 (Von Koschitzky 1992: 55; Llorente 1996: 23; Montani 2007: 50). Las mujeres Wichí llaman "lomo de suri o avestruz" (huantlaj huó, wanlohj-hu) a las líneas verticales quebradas en ángulos rectos; Montani señala que se trata de un motivo de difícil ejecución en las bolsas de malla de chaguar y poca frecuencia, pero de una forma estable; la variante más típica es aquella formada por líneas quebradas en relación especular en torno a una o varias cruces (Montani 2007: 47-48). Los diseños de damero representan el "caparazón de la tortuga" p'ataxlax para los Maká (Braunstein 1982: 451) y las mujeres Wichí los lla- man “caparazón de tortuga” (kitadni ahäs, chitahni-t' oj) (Von Koschitzky 1992: 54, 59; Montani 2007: 45). Las bolsas Wichí en enlazado simple de caraguatá/ chaguar llevan el diseño de triángulos, cuyo nombre es "orejas de mulita" (huak'atsaj kiotéi, huaqtsaj-ch'utey) (Von Koschitzky 1992: 46-47; Montani 2007: 46-47).

Como se puede observar, los nombres de los diseños presentes en las bolsas de caraguatá/ chaguar tejidas en malla o red, corresponden, en su mayoría a partes de animales, aunque también en algunos casos que no he mencionado acá, hacen referencia a semillas (Millán de Palavecino 1944; Braunstein 1982; Von Koschitzky 1992; Llorente 1996; Montani 2007).

Nos resulta relevante una observación que realiza Rodrigo Montani sobre las bolsas tejidas en malla rectangula-

7 Aclaramos que cuando aparecen dos formas de escribir el nombre del diseño en la lengua originaria, corresponden a las diferentes maneras que han sido escritas en la bibliografía citada. 
res de chaguar/ caraguatá usadas por los varones entre los Wichí. Señala que además de hilú, también se las llama lalhey ("su nombre"). Cita a John Palmer quien propone que el hecho de que las mujeres Wichí den bolsas cuadrangulares a sus hombres implica que ellas nombran a sus hombres con sus bolsas a través de los diseños predeterminados que aparecen en ellas. Montani se pregunta, entonces, si el hecho de que las mujeres entreguen bolsas a hombres que en los tiempos originarios tuvieron formas de animales no daría una explicación al repertorio de nombres de diseños de las mismas, cuya mayoría hacen referencia al reino animal (Montani 20o8: 173-174). De esta manera hay una asociación entre los bolsos enlazados de caraguata/ chaguar, los nombres de los diseños presentes en ellos y la escena mítica del origen de la humanidad según los Wichí, que permite pensar que las mujeres nombran a sus hombres con sus bolsos y tejen éstos como metáforas de los animales que ellos fueron (Montani 2008: 175).

Pensando en la relevancia señalada por Montani de los diseños que aparecen en las bolsas enlazadas de caraguatá, el nombre de los mismos y su significación mítica y social $\mathrm{y}$, considerando que se relevaron motivos y configuraciones de diseños similares en las bolsas tricotadas Wichí, se puede proponer que, aún elaboradas con una técnica procedente de la sociedad hegemónica, la presencia de tales diseños las hace parte de esta significación mítica y social, evidenciando aún más el complejo proceso de apropiación implicado en su elaboración.

\section{Las fajas “Toba del "Pilcomayo” de la colección Alfred Métraux de 1934}

En este apartado desarrollaré el estudio de una colección formada exclusivamente por 20 fajas atribuidas a los "Tobas del Pilcomayo" (Qom). Ésta colección fue comprada por el Museo Argentino de Ciencias Naturales "Bernardino Rivadavia” al etnógrafo suizo Alfred Métraux en el año 1934 (Catálogo de registro de objetos al Museo Argentino de Ciencias Naturales "Bernardino Rivadavia" 1929-1945).

En el año 1933, Métraux realiza un viaje en el que contactó con distintos grupos Qom del oeste de Formosa. Durante este viaje recorre el Estero Patiño con apoyo de la gendarmería argentina, sobre la margen derecha del río Pilcomayo, pasando por Fortín Salazar, Fortín Lugones, Salto
Palmar y Yoma (dominio del cacique Garcete), luego visita a los toba (Qom) del cacique Cernasol, establecidos en Labagan y llega a la misión anglicana cercana a Sombrero Negro, donde el misionero John Arnott lo contacta con Kedok, su informante básico para sus estudios de etnografía TobaPilagá (Bilbao 2002: 69-77).

Siguiendo a Gastón Gordillo, los Qom del noroeste de Formosa se distinguen de otras parcialidades Qom; una de las diferencias es idiomática. Una experiencia histórica que marcó profundamente a este grupo es la evangelización iniciada en 1930 por misioneros ingleses. Ello explica que éste sea el único grupo toba (Qom) en la Argentina cuya identidad religiosa es predominantemente anglicana, a diferencia de las diversas identidades pentecostales hoy dominante en el Chaco oriental (Gordillo 2005: 15-16). Este antropólogo señala que cuando en 1930 los misioneros ingleses Alfred Leake y Alec Sanderson comenzaron su trabajo en lo que luego sería Misión El Toba, ubicada a un par de kilómetros de Sombrero Negro, se fueron consolidando varias comunidades junto al río que agrupaban a gente de distintos grupos tobas (Qom). Las más importantes fueron Laguna Martín (con gente chiyadi'pí), Misión El Toba (con gente kedoco'pí), La Bolsa (loliagadi'pí), Cañaveral (jelcaic'pí y mañigodi’ pí), Jesús María (con gente piogodi’ pí) y Laguna de las Paces. Gordillo señala que los sábados, mucha gente de estas comunidades iba a Misión El Toba para asistir al culto del domingo y además vender cueros de animales en Sombrero Negro y artesanías en el almacén de la misión (Gordillo 2005: 78-79). Es en el año 1933 cuando Alfred Métraux visita la misión anglicana y permanece realizando estudios y formando colecciones en ella. Probablemente, las fajas compradas en 1934 por el Museo Argentino de Ciencias Naturales a Métraux hayan sido parte de estas colecciones.

En primera instancia, haré una breve descripción de las mismas basada en los resultados del estudio de diversos aspectos de su materialidad. Todas ellas presentan estructuras textiles de tejido en faz de urdimbre con urdimbres complementarias (doble faz) alternas en relación $1 / 1$ y 2/2. ${ }^{8}$ Se caracterizan por presentar el orillo de urdimbre en uno de sus extremos, a través del cual pasa un lazo retorcido o trenzado y, en el extremo opuesto, flecos estructurales retorcidos o trenzados cuyos extremos no se encuentran cortados (Figura 8); los tejidos han sido retirados del telar sin ser cortados. ${ }^{9}$ Todas ellas están elaboradas con hilos de lana formados por dos cabos Z/S, composición del hilado que se

8 Las denominaciones se basan en las propuestas por Rowe (Rowe 1977, 2006).

9 La elaboración de tejidos en cuatro orillos que pueden ser retirados del telar sin necesidad de cortarlos es una técnica que se registra entre distintos pueblos originarios de Sudamérica con anterioridad a la llegada de los españoles hasta nuestros días. En el caso específico de los pueblos del Gran Chaco, la tecnología empleada es un tipo de telar conformado por un marco con una cuerda tensa extendida entre los palos transversales; sobre dicha cuerda las urdimbres se enlazan de forma tal que, al terminar el tejido, la cuerda se retira obteniendo un tejido con sus cuatro orillos (ver Métraux 1946) 


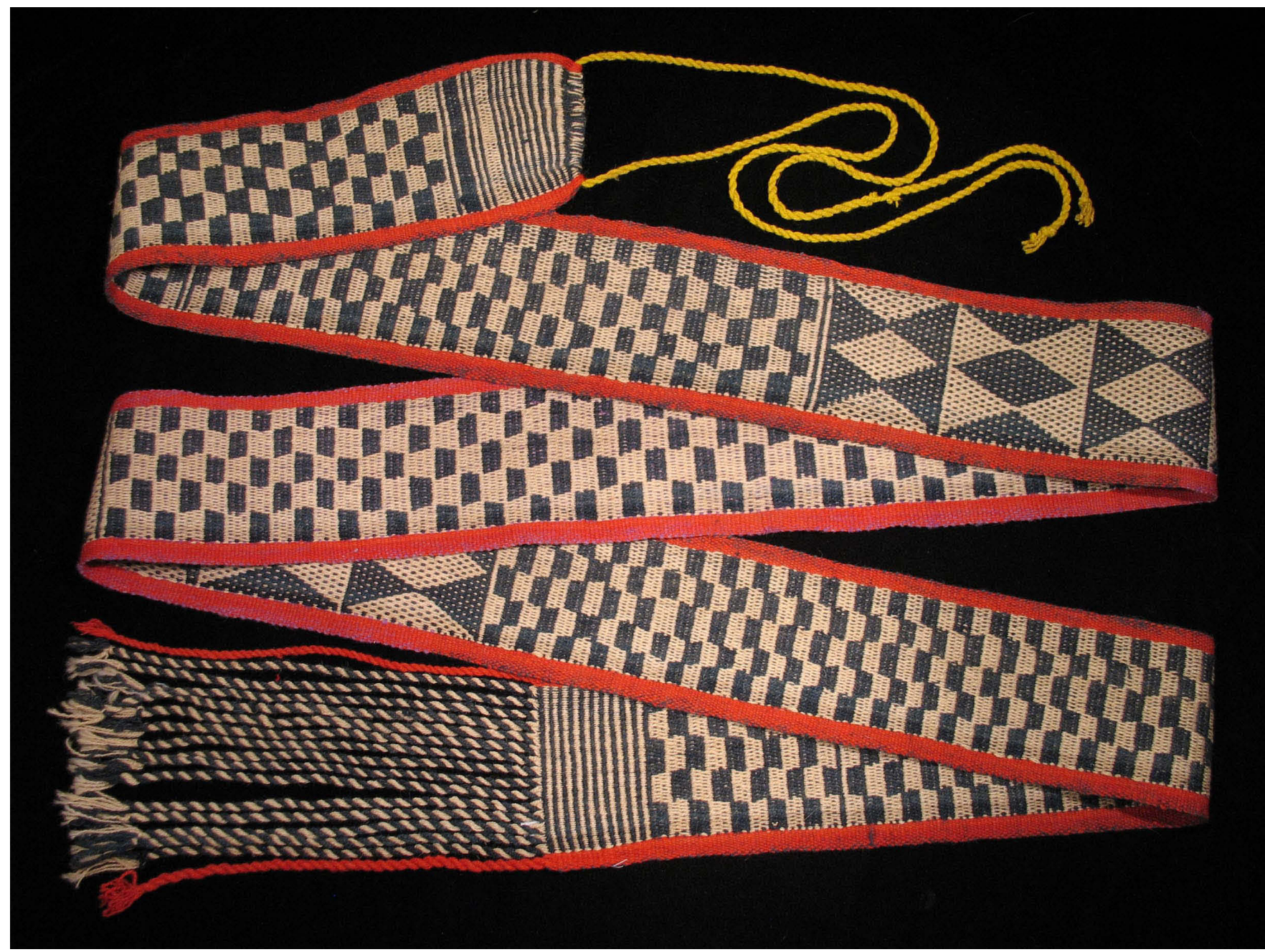

Figura 8- Faja de lana- "Toba del Pilcomayo"- “Toba del Pilcomayo” (Qom)- Colección comprada a Alfred Métraux, 1934- Museo Etnográfico “J. B. Ambrosetti”. Fotografía: M. A. Elías

releva en los hilados de lana de distintos pueblos chaqueños (Elías 2012 : 31-32).

Siguiendo las características de las estructuras textiles y materia prima de estas fajas, las descripciones sobre el uso de objetos similares entre distintos pueblos indígenas del Gran Chaco, así como las evidencias de uso en fajas con características similares, he definido seis variables para el registro de sus evidencias de uso: 1) arrugas y pliegues horizontales en el sentido de la urdimbre; 2) desgaste o abrasión en el cuerpo; 3) roturas, desestructuración, arreglos en el cuerpo; 4) roturas, desestructuración, arreglos en los flecos estructurales; 5) roturas, desestructuración, arreglos en el lazo del orilla de urdimbre; 6) manchas.

En cuanto a las variables 1) y 2), no se ha registrado en ninguna de las fajas de la colección la presencia de arrugas y pliegues horizontales o indicios desgaste o abrasión. Considerando la variable 3), sólo en una de las fajas se ha observado rotura y faltantes de algunas urdimbres sobre uno de los orillos de trama cercano a los flecos estructurales. Ninguna de las fajas presenta la presencia de la variable 4). En cuanto a la 5), en una de ella se observó la rotura en dos fragmentos del lazo del orillo de urdimbre y la unión de ambos por anudado; una segunda faja presenta la faltante del lazo; una tercera faja presenta el lazo retorcido desestructurado; finalmente, dos fajas no presentan roturas, desestructuración ni arreglos en sus lazos, pero sí el anudado de los mismos. Sólo una de las fajas del corpus evidencia una mancha negra en el cuerpo (variable 6).

De todo el conjunto, sólo la faja, con número de inventario anterior 34-3, muestra la presencia de dos de las variables: rotura y arreglo por anudado del lazo (Figura 9) y evidencia de rotura y faltantes de urdimbres en un sector del cuerpo. En el resto de las fajas del corpus, las variables sólo aparecen en orden de una por faja. Del conjunto de 20 fajas, sólo 5 presentan una de estas variables. A partir de estos resultados, se puede señalar que son casi inexistentes los 


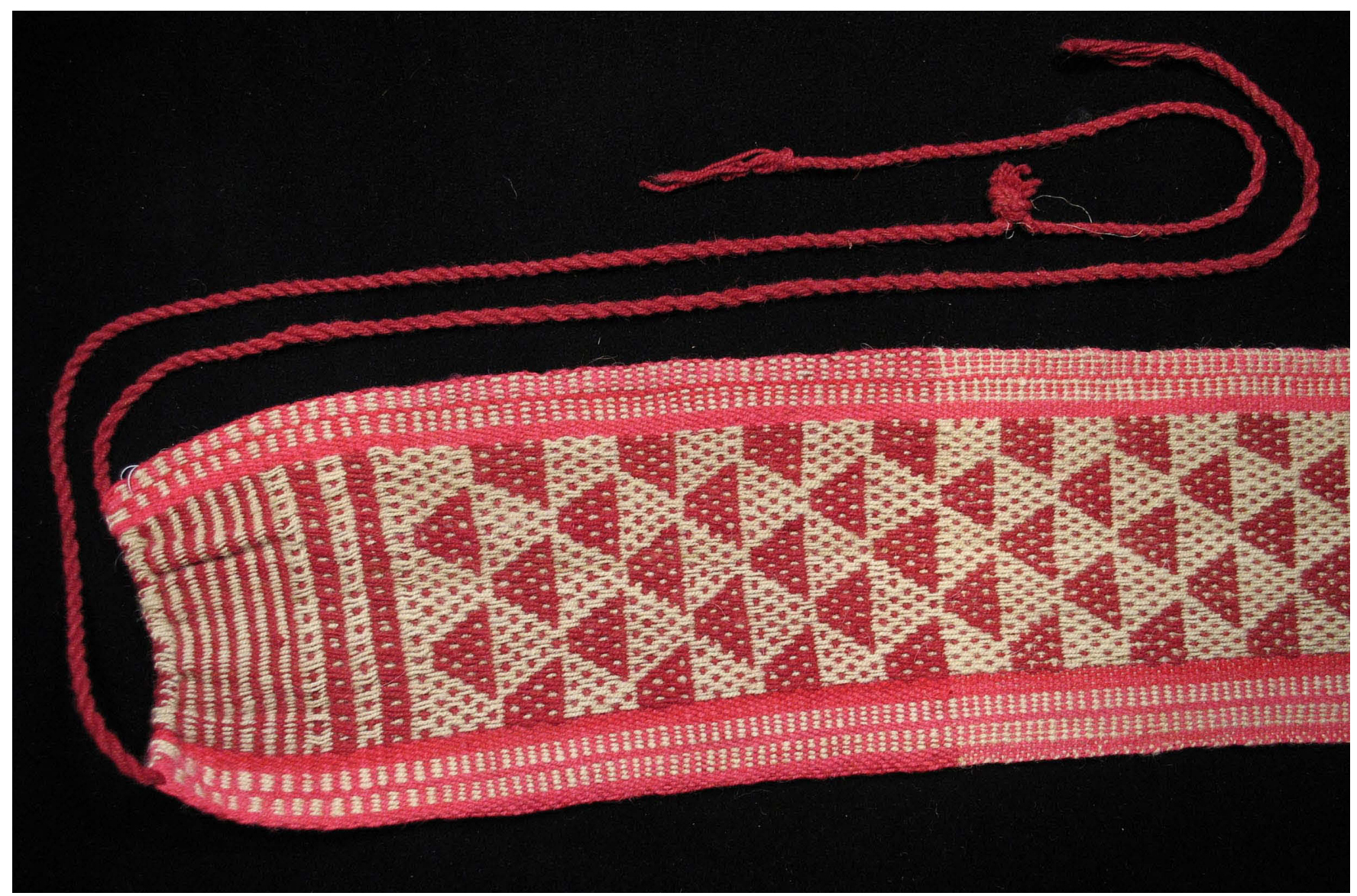

Figura 9- Detalle de rotura y anudado para arreglo del lazo de la faja 34-3- "Toba del Pilcomayo" (Qom)- Colección comprada a Alfred Métraux, 1934- Museo Etnográfico “J. B. Ambrosetti”. Fotografía: M. A. Elías.

indicios de uso previo de la mayoría de las fajas que conforman esta colección, sobre todo considerando que ninguna de ellas presenta pliegues de uso entorno a la cintura y desgaste o abrasión en algún sector del cuerpo.

Esto nos permite plantear la posibilidad de que entre los fines para los que fueron producidas estaba incluida su probable venta. En relación con esto, en su libro Nosotros vamos a estar acá para siempre. Historias tobas, Gastón Gordillo menciona la venta de artesanías en el almacén de la Misión anglicana El Toba por parte de las mujeres Qom del oeste de Formosa (Gordillo 2005: 79). Transcribo lo contado por la gente toba-qomle'ec a Gastón Gordillo en cuanto a la creación y la vida en relación con la Misión El Toba:

"Venía uno que se llama Enrique Grubb ${ }^{10}$. Eran dos los que venían. Venía Alfredo ${ }^{11}$ con una mula blanca y el otro misionero con una mula baya. (...) Hasta que terminaron una casita, dos, tres, no sé cuántas. Entonces recién hicieron trabajar a la gente para cortar adobe. Recién hicieron una casa linda. Y bueno, ya había misionero. Empezó a enseñar. Había escuela. Hizo todo; hizo un boliche para comprar las artesanías: yica, faja, poncho, alfombra, vincha, piola. Todo compraban. (...) (Emilio Rivero, en Vaca Perdida, 1999)." (Gordillo 2005: 85; el subrayado es mío)

"Alfredo compraba artesanías, porque tenía un almacén. (...) Las mujeres meta trabajar con las artesanías. En esa época el hombre no tenía trabajo, pero una mujer tenía trabajito. (...) Les daba plata a las mujeres, no a los hombres. Era el trabajo de ellas, entonces compraban algo. (Fabreciana Luis, en Vaca Perdida, 1996)" (Gordillo 2005: 86; el subrayado es mío)

10 Misionero inglés (Gordillo 2005: 79)

11 Misionero inglés cuyo nombre era Alfred Leake. Otros misioneros ingleses fueron Alfred Tebboth y John Arnott (Gordillo 2005: 79) quien pone en contacto a Métraux en su viaje de 1933 con su informante qom Kedoc (Bilbao 2002: 69-77). 
"Alfredo compraba asinito, no era mucho. Veinte centavos, cuando valía la plata. (...) Le vendían por ahí la alfombra a la señora de Alfredo y después ella compraba remedios para traer, para que no falten remedios. Ella le avisaba a la gente: "Bueno, les voy a comprar artesanías. Entonces cuando las vendo voy a comprar los remedios”. Estaban contentas, bien contentas, las mujeres. Se amontonaban bien en el almacén. El día sábado ¡uh! (Cristina Saravia, Laguna Cancino, 1999) (p. 86)

A partir de esta información, se puede proponer que, la mayoría de las fajas de esta colección - atribuidas a los pueblos “Tobas del Pilcomayo" (Qom) y probablemente recolectadas por Alfred Métraux en su viaje a la zona del noroeste de Formosa en 1933, en contacto con los misioneros anglicanos presentes en la región - fueron producidas para su venta/ intercambio con los misioneros, entre otros fines. Recordemos que Emilio Rivero cuenta a Gordillo que en la Misión El Toba Alfred Leake hizo un boliche para comprar las artesanías: yica, faja, poncho, alfombra, vincha, piola (Gordillo 2005: 86).

Appadurai define la situación mercantil en la vida social de cualquier "cosa" como la situación en la cual su intercambiabilidad (pasada presente o futura) por alguna otra cosa se convierte en su característica socialmente relevante (Appadurai 1991: 29). En el caso de este conjunto de fajas, se podría aplicar la definición de Appadurai. Lo mencionado por Fabriciana Luis lo reafirma: "Alfredo compraba artesanías, porque tenía un almacén. (...) Las mujeres meta trabajar con las artesanías. (...) Les daba plata a las mujeres" (Gordillo 2005: 86).

Usando las palabras de Phillips y Steiner, se puede pensar que estas fajas, de alguna manera, están inscriptas en modos occidentales de producción mercantil, de hecho dicha inscripción ha sido uno de los aspectos más importantes de la extensión global de poder colonial occidental (Phillips y Steiner y 1999: 4). Esta parte de su naturaleza, mercantil, no ha sido evidenciada en su historia de recolección ni en la documentación que sobre ellas se ha llevado a cabo hasta el momento en el Museo Etnográfico “J. B. Ambrosetti”. Sin embargo, existen ejemplos de que los etnógrafos compraban objetos y que los indígenas del Gran Chaco los vendían. Salvador Debenedetti, para mencionar un caso temprano, en su expedición al ingenio Ledesma en el año 1909, menciona el haber comprado objetos a los indígenas del Gran Chaco que iban allí como mano de obra estacional (Carta de Debenedetti a Ambrosetti, Ledesma, 25-09-1909, Archivo Debenedetti, Archivo Fotográfico y Documental, Museo Etnográfico “J. B. Ambrosetti”).
Por lo tanto, probablemente, la producción de estas fajas estuvo destinada a un mercado externo a los "Toba del Pilcomayo" (Qom), y ello no pone en cuestión su autenticidad, en tanto la producción de las mismas, tal como intenté dar cuenta al inicio de este apartado con su descripción, evidencia la presencia de saberes, prácticas y conocimientos de gran trascendencia entre estos grupos del noroeste de Formosa en particular y entre distintos grupos del Gran Chaco en general. Sin embargo, resulta relevante dar cuenta de esta posibilidad de pensarlas como "mercancías", en tanto recupera las relaciones sociales históricas en las que fueron producidas, es decir, la elaboración de objetos por parte de las mujeres Qom del oeste de Formosa para ser vendidos a los misioneros anglicanos. En palabras de Phillips y Steiner:

\begin{abstract}
"Las acusaciones de inautenticidad estaban también basadas en la aserción que las mercancías [commodities] eran producidas para mercados externos y no usadas por los mismos productores. Este alegato ignoraba hechos llanos. Las poblaciones colonizadas alrededor del mundo a menudo vestían el mismo tipo de prendas y ornamentos que vendían como souvenir, y muchas formas de expresión estéticas en las comunidades indígenas fueron profundamente transformadas por el involucramiento intensificado de sus productores en la producción de mercado.” (Phillips y Steiner 1999: 10).
\end{abstract}

\section{Conclusiones y consideraciones finales}

Este artículo se denomina "Colecciones textiles etnográficas del Gran Chaco Sudamericano del Museo Etnográfico 'J. B. Ambrosetti' y el estudio de su materialidad: un desafío a la mirada occidental sobre los 'otros no-occidentales'”. El análisis de distintos aspectos de la materialidad de los objetos textiles que integran las colecciones del Museo ha implicado el cuestionamiento de la forma de pensar - documentar investigar y clasificar la cultura material textil de las poblaciones originarias del Gran Chaco Sudamericano y, con ello, las representaciones sobre sus productores.

El relevamiento de la técnica de tricotado para la elaboración de las bolsas de lana atribuidas a distintos pueblos del Gran Chaco presentes en las colecciones, ha planteado la necesidad de dar cuenta y pensar la presencia de elementos materiales - técnica - procedentes de la sociedad hegemónica en los objetos textiles etnográficos chaqueños. Más que cuestionar su autenticidad o pensar que implica la pérdida de tradiciones, el análisis de sus aspectos materiales como formato y configuraciones de diseños, nos ha permitido recuperar sus contextos coloniales de producción 
y dar cuenta de complejos procesos de apropiación y agencia indígena implicados en su elaboración en dichos contextos. Por otro lado, el relevamiento de los documentos de registro de ingreso de las mismas al Museo y sus posteriores descripciones y clasificaciones, evidencia lo señalado por Clifford respecto a que lo híbrido no ha sido empleado como categoría de clasificación en las prácticas de los museos occidentales.

En relación con esto basta con mencionar que en los catálogos de ingreso de objetos, estas bolsas son denominadas "bolsas de lana" o "bolsas de lana (tipo rectangular)", sin señalar su técnica particular de elaboración (Catálogo de ingreso de objetos al Museo de Ciencias Naturales "Bernardino Rivadavia”, 1929-1945). Por otro lado, la documentación posterior expresada en la Base de datos hasta el momento en que comencé a estudiar las colecciones textiles del Gran Chaco, sólo mencionaba en el campo de información Técnica de manufactura la categoría “tejido”. El dar cuanta de esta estructura textil en el inventario y la documentación de este corpus de bolsas de los pueblos originarios del Gran Chaco nos corremos de la exigencia de "pureza" aplicada por Occidente a las poblaciones no-occidentales.

Algo similar se puede señalar para el corpus de fajas recolectadas por Alfred Métraux entre los "Tobas del Pilcomayo" (Qom). Hasta el momento, esta colección ha sido empleada para estudios de la cultura material de los grupos Qom que recuperan sus funciones al interior de dichas sociedades, las cuales son valorables y aportan información sobre este patrimonio, sin embargo, no se ha dado cuenta de sus contextos de recolección y producción y cuáles eran los complejos vínculos de quiénes las crearon con la sociedad hegemónica. Las casi nulas evidencias de uso de dichas fajas permiten plantear la pregunta sobre el destino de su producción, ingresando en nuestra representación de sus productores y de su cultura material el concepto de "mercancía” o del estado mercantil de las mismas. El aplicar esta categoría a estos objetos guardados en las colecciones del Museo Etnográfico no pone en duda su autenticidad ni su valor, por el contrario, permite dar cuenta de sus contextos históricos de producción, en los que los Qom del oeste de Formosa estaban relacionados con los misioneros anglicanos que establecieron una Misión en su región, lo cual implicó modificaciones en sus formas de producción y consumo de objetos.

James Clifford propone pensar a los museos como "zonas de contacto", recuperando el concepto de Mary Louis Pratt en su libro Ojos imperiales: viajes y transculturación. La expresión "zona de contacto" es un intento de convocar la copresencia espacial y temporal de sujetos previamente separados por disyunturas geográficas e históricas y cuyas trayectorias se cruzan ahora. Una perspectiva de contacto enfatiza de qué modo los sujetos están constituidos en y por sus relaciones recíprocas, subrayando la copresencia, la interacción, la trabazón de entendimientos y prácticas, a menudo dentro de relaciones de poder radicalmente asimétricas. "Cuando se ve a los museos como zonas de contacto, su estructura organizadora como colección se vuelve una relación permanente histórica, política, moral: un juego de tira y afloja, un conjunto de intercambios cargados de poder." (Clifford 1999: 238). Esta relación permanente histórica, política, moral, este conjunto de intercambios cargados de poder es lo que, considero, queda evidenciado en el presente trabajo sobre dos corpus específicos de las colecciones textiles del Gran Chaco Sudamericano del Museo Etnográfico “J. B. Ambrosetti”, al punto que me atrevo a proponer que los objetos que las integran son ellos mismos "zonas de contacto" en tanto su materialidad constituye un indicio de copresencia, interacción, trabazón de entendimientos y prácticas, en el marco de relaciones de poder radicalmente asimétricas.

\section{Referencias citadas}

Arenas, Pastor

1997 Las bromeliáceas textiles utilizadas por los indígenas del Gran Chaco. Parodiana, 10 (1-2): 113-139.

2003 Etnografía y Alimentación entre los TobaNachilamole\#ek y Wichí-Lhuku'tas Chaco Central (Argentina). Edición Pastor Arenas, Buenos Aires.

Appadurai, Arjun

1991 Introducción: Las mercancías y la política del valor. En La vida social de las cosas. Perspectiva cultural de las mercancías, editado por Arjun Appadurai, pp. 1787. Grijalbo, México.

Braunstein, José

1982 El problema de la significación de la cultura material de los indios Maká. Tesis de Doctorado, Facultad de Filosofía y Letras, Universidad de Buenos Aires.

Berlo, Janet

1996 Beyond Bricolage: Women and Aesthetic Strategies in Latin American Textiles. En Textiles Traditions of Mesoamerica and the Andes, editado por Margot Blum Schevill, Janet Catherine Berlo y Edward B. Dwyer, pp. 437-479. University of Texas Press, Austin, TX.

Bilbao, Santiago

2002 Alfred Métraux en la Argentina. Infortunios de un antropólogo afortunado. Comala, Caracas.

Boccara, Guillaume

2005 Antropología diacrónica. Dinámicas culturales, procesos históricos y poder político. Nuevo Mundo Mundos Nuevos. Recuperado de https://nuevomundo. revues.org/589 
Museo Argentino de Ciencias Naturales

1929-1945 Catálogo de inventario de objetos etnográficos del Museo Argentino de Ciencias Naturales "Bernardino Rivadavia".

Clifford, James

1999 Itinerarios transculturales. Gedisa, Barcelona.

1995 Dilemas de la cultura. Antropología, literatura $y$ arte en la perspectiva posmoderna. Gedisa, Barcelona.

Debenedetti, Salvador

1909 Carta de Salvador Debenedetti a Juan Bautista Ambrosetti, Ledesma, 25 de septiembre de 1909. Archivo Debenedetti, Archivo Fotográfico y Documental, Museo Etnográfico “J. B. Ambrosetti”, Buenos Aires.

Elías, Mariana Alfonsina

2008 El universo textil etnográfico del Chaco argentino: los tejidos chaqueños a principios del siglo XX. Informe Final de Beca Individual del Fondo Nacional de las Artes. Buenos Aires.

2012 Textiles indígenas del Gran Chaco Sudamericano. En Textiles del Chaco. Catálogo del MEAB, Mariana Alfonsina Elías y Ariel Mencia, pp.28-105. Museo Etnográfico “Dr. Andrés Barbero", Fundación La Piedad, Asunción.

Emery, Irene

2009 The Primary Structures of Fabrics. Thames and Hudson, The Textile Museum, Washington D.C.

Gordillo, Gastón

2005 Nosotros vamos a estar acá para siempre. Historias tobas. Editorial Biblos, Buenos Aires.

Le Count, Cynthia

1990 Andean Folk Knitting. Traditions and Techniques from Peru and Bolivia. Dos Tejedoras Fibers Arts Publications, Minnesota.

Llorente, María Mercedes

1996 Tejiendo historia con piolas de chaguar. Formosa.

Métraux, Alfred

1946 Ethnography of the Chaco. En Handbook of South American Indians, 1, editado por Julian Steward, pp. 197-370. Smithsonian Institution, Washington D. C.

Millán de Palavecino, María Delia

1944 Forma y significación de los motivos ornamentales de las 'llicas' chaquenses. Relaciones de la Sociedad Argentina de Antropología, IV: 69-77.

1973 Tejidos Chaqueños. Relaciones (Nueva Serie), VII: 6583.
Montani, Rodrigo

2007 Formas y significados de los diseños de los bolsos enlazados por los wichí del Gran Chaco. Separata, 12: 35-66.

2008 Metáforas sólidas del género: mujeres y tejido entre los wichí. En Mujeres indígenas en la Argentina. Cuerpo, trabajo y poder, coordinado por Silvia Hirsch, pp.153-177. Biblos, Buenos Aires.

Ortner, Sherry

2016 Antropología y teoría social. Cultura, poder y agencia. UNSAM Edita, Buenos Aires.

Phillips, Ruth B. y Steiner, Christopher

1999 Art, Anthenticity, and the Baggage of Cultural Encounter. En Unpacking Culture. Art and Commodity in Colonial and Postcolonial Worlds, editado por Ruth B. Philllips y Christopher B. Steiner, pp.3-19. University of California Press, California.

Rowe, Anne

1977 Warp patterned weaves of the Andes. Textile Museum Washington D. C.

1997 Looping and Knitting. Textiles Museum, Washington D. C.

2006 Términos textiles en castellano. En Actas III Jornadas Internacionales sobre Textiles Precolombinos, editadas por Victória Solanilla Demestre, pp. 443-469. Grup d' Estudis Precolombins, Departamento de Arte de la Universidad Autónoma de Barcelona, Barcelona.

Schmidt, Max

1937 a Los Guisnais. Revista de la Sociedad Científica del Paraguay, IV (2): 1-35.

1937 b Los Tapietés. Revista de la Sociedad Científica del Paraguay, IV (2): 36-85.

Seiler-Baldinger, Annemarie

1994 Textiles. A classification of techniques. Smithsonian Institution Press, Washington D.C.

Susnik, Branislava

1982 Los aborígenes del Paraguay. Cultura Material. Museo Etnográfico “Andrés Barbero", Asunción.

Von Koschitzky, Mónica

1992 Las telas de malla de los Wichí/Mataco. Su elaboración, su función y una posible interpretación de los motivos. Centro Argentino de Etnología Americana, Buenos Aires.

Von Rosen, Eric

1924 Ethnographical Research Work during the Swedish Chaco-Cordillera Expedition, 1901-1902. Fritze Limited, Estocolmo. 